\title{
Control y administración de pesos y medidas en las ciudades del Imperio romano (Pars Occidentalis)
}

\author{
Antonio D. PÉrez Zurita \\ Grupo ORDO (Universidad de Córdoba) \\ antopezu@hotmail.com
}

\section{RESUMEN}

En este trabajo, analizamos cómo los miembros de la administración romana controlaron y gestionaron el sistema de pesos y medidas, tanto en la Urbs, como en los distintos municipios y colonias de la parte occidental del Imperio. Examinamos qué magistrados estuvieron al cargo de esta labor y las competencias que les fueron asignadas. Igualmente, evaluamos el grado de difusión que alcanzaron los instrumentos de medición romanos, cómo fueron financiados, así como los métodos usados y la participación de las diferentes autoridades gubernativas en su estandarización e implantación en el ámbito local. Por último, estudiamos el contexto espacial en el que se emplazaron estos instrumentos.

Palabras clave: Roma, ciudades, administración pública, instituciones, pesos y medidas.

\section{Control and Administration of Weight and Measures in the Cities of the Roman Empire (Pars Occidentalis)}

\begin{abstract}
In this paper, we examine how members of the Roman administration controlled and managed the weight and measure systems, both in the Urbs and in various towns and colonies in the Western Empire. We examine which magistrates were in charge of this task and the powers assigned to them. Similarly, we assess the expansion these measurement tools reached, how they were financed, as well as the methods used and the participation of various governmental authorities in their standardization and implementation at the local level. Finally, we study the spatial context in which these tools were located.
\end{abstract}

Key words: Rome, cities, public administration, institutions, weights and measures.

La difusión del modelo urbano es sin duda una de las mayores aportaciones de la cultura grecolatina a la Historia. En efecto, los habitantes de la Hélade y, más tarde, del Imperio romano, acudían a la ciudad como lugar de reunión para gestionar numerosas actividades entre las que destacaban el intercambio de mercancías. Desde los albores de civilizaciones como la mesopotámica o la egipcia, el comercio fue fiscalizado por diferentes autoridades o instituciones por motivos que en no pocas ocasiones exceden el marco de las políticas impositivas y hacendísticas. Así, por ejemplo, el control de 
la exactitud en los pesos y medidas utilizados garantizaba, tanto al comprador como al vendedor, la equidad de las transacciones comerciales. Nuestro objetivo en el presente trabajo será analizar cómo se administró el control de pondera y mensurae, centrando nuestra atención, especialmente, en las ciudades del Occidente romano.

Los ediles fueron con casi total seguridad los magistrados encargados, al menos durante parte de la República, de asegurar la exactitud de los pesos y medidas en los mercados de Roma ${ }^{1}$, probablemente como parte de sus competencias, bien en relación a la cura urbis, o con más seguridad a la cura de la annona. Así parece demostrarlo un famoso testimonio de Cicerón, que caracterizaba las funciones de los ediles como curatores urbis annonae ludorumque solemnium (leg. 3, 7). Sin embargo, debemos reparar en el sentido enormemente generalista de la cita del arpinate, dado que bajo la cura annonae podrían englobarse funciones muy diversas, tales como el abastecimiento de la annona, el control de las distribuciones de grano y la vigilancia de los mercados. En este último caso, a su vez, los ediles debían supervisar la calidad de los productos, su justo precio o que los pesos y medidas con los que se dispensaban los mismos fueran los correctos ${ }^{2}$. Y es precisamente de este último aspecto del que peor informados estamos, al menos si limitamos nuestro análisis a la Urbs.

En efecto, las fuentes son enormemente parcas a la hora de hacer referencia a las instituciones y el personal administrativo en general que se hizo cargo del control y la supervisión de los pesos y medidas en Roma. De hecho, el único testimonio literario que relaciona directamente a los ediles con nuestro objeto de análisis se lo debemos a Ulpiano, quien en sus comentarios ad Edictum cita a estos magistrados en relación a la destrucción de pesos y medidas falsas (Dig. 19, 2, 13, 8) 3 $^{\text {. Desconocemos por }}$ lo tanto cuestiones de enorme interés, como por ejemplo las diferentes instituciones y personal subalterno implicados en esa supervisión o si las distintas tareas que ésta conllevaba estuvieron encomendadas a un único responsable. No obstante, con las debidas precauciones, quizás podamos arrojar algo de luz sobre estas cuestiones. Tradicionalmente se ha especulado con la posibilidad de que la llamada lex Silia, una lex de ponderibus en forma de plebiscito que quizás pueda datarse entre el 287 y el 223-218 a.C. (con mayor probabilidad en los últimos años de este periodo) y que es-

1 En los mercados permanentes y seguramente también en los periódicos (nundinae), aunque relacionar la actividad de los ediles con este último tipo de mercados sea mucho más difícil de demostrar basándose en las fuentes. Téngase en cuenta que en el mundo griego y, posteriormente, en la parte oriental del Imperio, sí tenemos agoranomoi y panêgyriarchai encargados de la supervisión de este tipo de reuniones periódicas (De Ligt, 1993, 42-45). Sin embargo, no debemos olvidar que a pesar de que la historiografía ha establecido tradicionalmente paralelismos entre las actividades de los ediles y los agoranomos, estos cargos también poseen notables diferencias.

2 Tal y como expone Festo (p. 247M), aunque sin referirse concretamente a los ediles. Sobre el tema y las fuentes existentes en relación a estos magistrados, tanto para la Urbs como para los municipios y colonias hispanos, véase A. D. Pérez Zurita (2011, 66 ss. y 232 ss.). Las competencias de los ediles en relación a la vigilancia de los mercados también han sido objeto de análisis por parte de M. KuRYLOwICZ (2000, 439-456).

3 No obstante, determinados autores como Th. Mommsen o W. Liebenam contextualizaron este pasaje en el ámbito municipal (cfr. LAMBERTI, 1994, 366). La autora italiana reinterpretó el comentario ulpianeo en referencia a las actiones a emprender dentro de la locatio operis, es decir, en cuanto a las posibles irregularidades en la fabricación de pesos y medidas y la responsabilidad derivada de las mismas del locator y del conductor (EAD. 368 s.). 
tablece una estandarización de las medidas de áridos y líquidos, así como las penas a las que se debían enfrentar aquellos que infligieran la ley, reconocía a los ediles como los magistrados encargados de velar por la exactitud de pesos y medidas en Roma ${ }^{4}$. El problema es que en la trasmisión del texto, que debemos fundamentalmente a Festo, no se ha conservado ninguna referencia concreta a los magistrados que debían velar por el cumplimiento de esta ley, por lo que su relación con los ediles, aunque plausible, no deja de ser hipotética.

Lo que sí podemos afirmar sin temor a equivocarnos es que en el año 47 d.C., quizás bajo la edilidad de M. Articuleius y Cn. Turranius, al menos el primero de estos magistrados estaría encargado de tipificar los pesos en Roma ${ }^{5}$. Las muestras originales, que seguramente fueron custodiadas en el Capitolio en Roma, debieron servir como modelo para todo el Imperio romano, ya sea de manera directa o a través de copias custodiadas en otras comunidades provinciales a las que los centros de menor entidad podían acceder más fácilmente sin necesidad de trasladarse a la Urbs. Así lo confirman numerosos epígrafes hallados por todo el imperio con distintas referencias a los estándares supervisados por los ediles y que reproducimos en la siguiente tabla:

\begin{tabular}{|c|c|c|}
\hline Corpus & Comunidad & Fórmula \\
\hline CIL X, 8067.1 & Herculaneum & $\begin{array}{l}\text { Ponder(a) exact(a) [M(arco?)] Ar[ti] } \\
\text { culei[o] Cn(aeo) Tur(ranio?) aedil(ibus) }\end{array}$ \\
\hline CIL X, 8067.2 & Herculaneum & exacta ad Artic(uleianam) cura aedil(ium) \\
\hline CIL XIV, 4124.1 & Fidenae & $\begin{array}{l}\text { exact(a) ad Artic(uleianum) ius(su) } \\
\text { aed(ilium) }\end{array}$ \\
\hline CIL XIV, 4124.2 & Praeneste & iussu aed(ilium) exact(a) ad Artic(uleiana) \\
\hline$A E 1908,69$ & Thibursicum Bure & $\begin{array}{l}\text { iuss( }(u) \text { aedili(um) exacta ad Artic(uleiana) } \\
\text { p(ondera) }\end{array}$ \\
\hline$A E 1976,793$ & comunidad ignota & $\begin{array}{l}\text { me(n)sura exacta ad Articuleia(num) iussu } \\
\text { aediliu(m) }\end{array}$ \\
\hline ILS 8631 & comunidad ignota de la Regio I & p(ondus) Articuleia(num) iussu aedil(ium) \\
\hline ILS 8633 & comunidad ignota de la Regio VII & $\begin{array}{l}\text { p(ondera) ex(acta) ad Artic(uleianum) } \\
\text { ius(su) aed(ilium) }\end{array}$ \\
\hline ILS 8635 & Roma & Exacta ad X Articuleian(um) \\
\hline
\end{tabular}

Sea como fuere, el problema de la falsificación de los pesos y medidas oficiales en el mundo romano y los continuos intentos por parte de la administración central de mantener un sistema estandarizado y velar por el uso de sistemas de medición conforme a la ley es enormemente recurrente y tiene su reflejo en las fuentes. Así,

\footnotetext{
${ }^{4}$ Sobre la lex Silia o lex de ponderibus, véase J. D. Cloud (1985, 405-418 y 1996, 737-739).

5 En general la historiografía suele aceptar la existencia de una estandarización de pesos en el año 47 d.C., aunque el hecho de que se debiera a M. Articuleius como edil de esa anualidad sólo estaría confirmado por la inscripción CIL X, 8067.1, de la que no hemos encontrado otros paralelos. El resto de testimonios, como a continuación expondremos, documenta una "norma Articuleiana" o un "sistema Articuleiano" del que no se podría deducir con total seguridad si estuvo vigente antes del 47 d.C., ni si se debió realmente a la obra de un edil. Sobre esta fórmula y la existencia de un "sistema Articuleiano" véase G. GatTi (1881, 181-203).
} 
por poner algunos ejemplos de diferentes épocas, la conocida como lex Cornelia de falsis, aprobada en su mayor parte por Sila en el 81 a.C., establecía toda una serie de directrices para luchar contra la falsedad (falsum), incluyendo castigos para quienes falsificaran pesos o medidas ${ }^{6}$; Adriano dispuso en un decreto que la pena contra este delito fuera la condena a relegación en una isla (Dig. 47, 11, 6, 1 y 48, 10, 32, 1); $L$. Turcius Apronianus, praefectus urbi en el año 363 d.C. aprobó un edicto en el que trataba de poner fin a cálculos estimatorios (digitis conludentibus) y obligaba al uso de pesos en la venta de corderos en los mercados (sub exagio pecora vendere) ${ }^{7}$.

En relación a esta última cuestión es de enorme interés la interpretación de una inscripción que recoge las resoluciones tomadas por un funcionario de la administración central, seguramente Cl(audius) Iulianus, prefecto de la annona en los primeros años del s. III d.C., sobre un conflicto entre los navicularii de Arlés y los mensores de Ostia (CIL III, 14165.8, de Beirut) ${ }^{8}$. El problema radicó, al parecer, en el hecho de que las mediciones y/o el pesaje del grano en el puerto de salida de la mercancía no concordaba con las cifras facilitadas por los mensores de Ostia, seguramente por las diferentes unidades de medida utilizadas en distintas partes del Imperio, aunque tampoco debemos olvidar los posibles fraudes, que harían necesaria una medición en el puerto de carga y de descarga de los productos, así como de documentos que certicaran dichas cantidades 9 . La administración central resolvió las reivindicaciones de los navicularii de Arlés obligando a transportar una barra de hierro con las medidas usadas en el puerto de carga que permitiera su correspondencia con las medidas utilizadas en el puerto de descarga del grano. Como podemos apreciar, pese a los intentos de estandarización de pesos y medidas, continuaron utilizándose diferentes sistemas, lo que en ocasiones provocaría actos fraudulentos como el que estamos comentando.

En cuanto a la existencia de subalternos que estuvieran a las órdenes de los ediles y ayudasen a estos magistrados a controlar el cumplimiento de la ley en lo relativo a pesos y medidas en la Urbs, debemos decir que los testimonios disponibles son casi inexistentes. Sabemos que Augusto dividió en el 7 a.C. las cuatro regiones existentes en Roma en catorce circunscripciones que fueron distribuidas a suertes para su administración por los ediles, tribunos de la plebe y pretores (Cass. 55, 8, 7). Por otra parte, conocemos que los ediles tenían potestad para nombrar en cada distrito a encargados de determinadas tareas como la vigilancia de los cursos de agua y de su salubridad (Frontin. aq. 97). Además, nuestros magistrados contaban con personal subalterno para administrar determinadas competencias relacionadas con los mercados, como por ejemplo dos guardias que confiscaban los alimentos cuya venta estaba prohibida por las leyes suntuarias (Suet. Iul. 43). Por lo tanto, ya fuera mediante

${ }^{6}$ Cfr. G. Rotondi $(1912,356)$ y A. Berger $(1953,467)$. No obstante, es posible que la ley original no tuviera referencias a la falsificación de pesos y medidas, sino que éstas se incorporaron posteriormente, quizás en el principado de Trajano o Adriano (cfr. KuRYLowicz, 2000, 448).

7 El decreto se nos ha conservado en la inscripción CIL VI, 1770 (Roma). Sobre el significado de la expresión "digitis conludentibus", véase M. GARCía Morcillo (2005, 93 s.). Sobre el personaje vid. PLRE I, 88-89.

8 Sobre la misma, véase M. CORBIER (2006, 233-256), a quien seguimos en el comentario que realizaremos a continuación. Por desgracia la inscripción está mutilada, lo que nos impide entender ciertos detalles sobre la causa expuesta en el texto de la misma.

${ }^{9}$ Cfr. C. CoRTi $(2001 \mathrm{a}, 145)$. 
encargados nombrados por los ediles ex professo, con la ayuda de subalternos o con otros funcionarios menores de la administración, estos magistrados podían controlar el cumplimiento de la ley respecto a los pesos y medidas. En este sentido es interesante una inscripción datable en los primeros años de nuestra Era en la que tres magistri vici donan un juego de pesos que debió estar custodiado en el Forum Boarium y que años después fue revisado para ajustarlo a los estándares legales (CIL VI, 282). No sería descabellado por lo tanto pensar, que estos magistri actuaran bajo la supervisión de los ediles que estuvieran al frente de la regio o las regiones en las que estaba situada el Forum Boarium y sus alrededores ${ }^{10}$.

Por otra parte, la epigrafía nos informa sobre diversos estándares que fueron realizados -al margen de los ediles- por otros magistrados a lo largo de la historia de Roma. Un ejemplo de ello podría ser el de Q. Iunius Rusticus, praefectus urbi que durante el ejercicio del cargo, probablemente en el 161 d.C., debió restablecer el sistema de pesos y medidas ${ }^{11}$; o D. Simonius Proculus Iulianus que, desempeñando el mismo cargo que el personaje anterior, hizo lo propio entre los años 239 y 254 d.C. ${ }^{12}$ Un siglo más tarde, Amiano Marcelino nos informa de que en el año 367 o 368 d.C. el praefectus urbi Vettius Agorius Praetextatus restableció los pesos y medidas existentes en Roma ${ }^{13}$ (Amm. 27, 9, 10).

Estos testimonios apoyan nuestra hipótesis, puesta de relieve ya por otros especialistas ${ }^{14}$, de que en Roma los ediles debieron desvincularse de la supervisión y estandarización de pesos y medidas en algún momento entre mediados del s. I y el s. II d.C., asumiendo esas competencias el praefectus urbi de la ciudad ${ }^{15}$. Ello encaja perfectamente en la evolución histórica del sistema político-administrativo de la Urbs, dado que a partir de las reformas llevadas a cabo por Augusto la edilidad va perdiendo prácticamente todas sus competencias, o al menos las de mayor importancia, en beneficio de los funcionarios creados por el primer emperador ${ }^{16}$.

${ }_{10}$ Los límites del Forum Boarium con respecto a la división administrativa en regiones adoptada por Augusto no está todavía clara (RichARDSON, 1992, 163).

11 Como bien testimonian los numerosos epígrafes sobre pondera aparecidos por todo el Imperio: CIL II, 4962.2; V, 8119.1; IX, 6088.1; X, 8068.5a-d; XI, 8135; XIII, 10030.10f; $A E$ 1901, 245; 1908, 70; 1911, 216. Sobre Q. Iunius Rusticus, véase G. AlföLdy $(1977,287)$ y $P I R^{2}$ I 814.

${ }^{12}$ ILS 8627. Sobre el personaje, véase $P I R^{2} \mathrm{~S} 748$.

13 Sobre el pérsonaje, véase PLRE I, 722-724.

14 Por ejemplo, S. Ruciński (2009, 101 s.) y O. F. Robinson (1992, 132-134).

15 Además, tenemos un documento en el que aparece M. Rutilius Lupus, prefecto de la annona, encargado de emitir pondera $(A E$ 1940,38), lo que ha llevado a algunos especialistas a afirmar que dichos magistrados tuvieron competencias en la materia después de los ediles y antes de que fueran asumidas por el praefectus urbi; mientras que otros investigadores prefieren pensar que el prefecto de la annona únicamente supervisó los pondera asignados a su servicio. Cfr. para estas hipótesis C. CoRTI (2001a, 158 s.) y C. BERRENDONNER (2009, 354 s.).

$16 C f r$. A. D. Pérez Zurita (2011, 73 s.). El hecho de que no contemos prácticamente con fuentes que testimonien ediles desarrollando sus competencias en la Urbs a partir de la dinastía flavia, así como de que las competencias que antes eran desarrolladas por estos magistrados fueran desempeñadas por funcionarios imperiales, no significa que la edilidad fuera desprovista por completo de sus funciones, aunque sí de aquellas que podríamos denominar de "alta supervisión". Por poner sólo un ejemplo la inscripción CIL VI, 1648 (=41296) documenta una dedicación por parte de los escribas de los ediles curules a un funcionario imperial ignoto que, entre otros cargos, fue procurator Miniciae et macelli magni, es decir, encargado del reparto del frumentum y de uno de los macella más importantes de la 
Por otra parte, sería interesante detenernos, aunque sólo sea de manera breve, en el proceso mediante el cual las autoridades romanas hicieron extensible la normalización o estandarización de los pesos y medidas a todas las comunidades del Imperio romano. Ya hemos observado con anterioridad que los pesos y medidas originales se custodiaban en la propia Urbs y a ellas se adecuaban las copias realizadas para su utilización en los municipios y colonias, como bien atestiguan numerosas incripciones repartidas por todo el territorio bajo dominio romano ${ }^{17}$. Generalmente los soportes son inscritos con una lacónica fórmula del tipo exacta in Capitolio, aunque en ocasiones nos dan información más extensa e inequívoca del proceso que debía seguirse para la validación de las copias, como, por ejemplo, I(n) capitolio esaminata (CIL XI, 6727.1) o Mensurae ad exemplum earum quae in Capitolio sunt (ILS 8627). Pero no sólo en el Capitolio debieron existir unas muestras de pesos y medidas que sirvieran de modelo a todas las comunidades del Imperio romano. Conocemos que, al menos en el templo de Cástor, también existieron unos juegos originales, aunque las referencias epigráficas están menos extendidas que en el caso de las copias realizadas a partir de los originales conservados en el Capitolio ${ }^{18}$.

Lo que sí parece seguro, a pesar de lo que a priori pudiera pensarse, es que las autoridades romanas comprobaron con relativa frecuencia que las copias de pesos y medidas no habían sido manipuladas y que continuaban cumpliendo los preceptivos

capital. Como podemos comprobar, en la segunda mitad del s. III d.C., fecha en la que se dataría esta inscripción, los ediles curules mantenían al menos parte de su equipo de subalternos y éstos, además, pudieron estar directamente relacionados con funcionarios imperiales que desempeñaban competencias que en época republicana estaban bajo la supervisión de los ediles. Sobre la lectura de esta fragmentada inscripción, véase H.-G. Pflaum $\left(1960, n^{\circ} 279\right)$ y P. Sabbatini Tumolesi (1988, no 21). Finalmente, dos testimonios del Digesto $(47,11,6,1-2 ; 48,10,32,1)$ en relación a la falsificación de pesos y medidas, pueden estar haciendo referencia a competencias de los ediles -aunque éstos no se citan expresamentey podrían demostrar que nuestros magistrados tuvieron competencias en la materia al menos hasta el primer tercio del s. II d.C. (cfr. KuRYLOwicz, 2000, 447-449).

17 Por citar sólo algunos ejemplos ilustrativos de la relativa difusión geográfica de este tipo de epígrafes: CIL X, 8067.3 (Herculaneum, Regio I); AE 1903, 346 (Carnuntum, Pannonia Superior); AE 1989, 475 (Valentia, Hispania Citerior); ILS 8628 (Roma).

18 Así, por ejemplo, CIL V, 8119.4a-h (Aquileia, Regio X); CIL XIII, 5451a = 10030.14b (Vesoul, Germania Superior); AE 1888, 87 a-e (Brimeux, Lugudunensis); AE 1982, 818a-c (Gorsium, Pannonia Inferior); AE 2001, 1582 (Virunum, Noricum); P. REINARD, 2008, 291 y 2009, 161 (tres pesos de bronce de procedencia ignota). Como ya advirtió F. Serrao (2000, 38 y n. 20), llama la atención que cerca del templo de Cástor existiera un mercado de esclavos, actividad regulada precisamente por los ediles y que está bien documentada gracias a los testimonios conservados sobre el edictum aedilium curulium. Además, debemos añadir que ese mismo templo sirvió como depósito o "caja fuerte" de los argentarii, razón de suficiente peso como para justificar la existencia de unos pondera originales en el recinto. Por último, se han encontrado pesos broncíneos con la inscripción de un numeral seguido de la expresión templ(um) Opis Aug(ustae), lo que podría llevar a pensar que en el templo de Ops en Roma, pudieron custodiarse otros originales (ILS $8637 \mathrm{a}-\mathrm{b}$ ). Sin embargo, pensamos que esa inscripción sería más bien un indicativo de que la propiedad de esos pesos era del templo, dado que la ausencia de expresiones tales como exactum ad o iussu -que sí tenemos testimoniada para el Capitolio o el templo de Cástornos impide confirmar la existencia de otro juego de pesos originales en el templo de Ops. Finalmente, tampoco debemos olvidar la relación que otras deidades del panteón romano pudieron tener con los pesos y medidas en general. A este respecto recordaremos la inscripción erigida en honor de Hércules ponderum hallada en Roma (CIL VI, 336) o los pondera auraria et argentaria consagrados a esta misma divinidad por tres magistri vici también en la Urbs (CIL VI, 282). Por último, no nos puede extrañar la asociación de Hércules con los pesos y medidas, dada su relación con las actividades comerciales. 
estándares. Ello puede deducirse de una inscripción hallada en el Forum Boarium en la que se recuerda la donación de pondera auraria et argentaria y su comprobación y ajuste conforme a los estándares ocho años después ${ }^{19}$.

Más difícil de dilucidar es el proceso mediante el cual los pesos y medidas conservados en la capital se difundieron como estándares por todo el Imperio romano. Parece inverosímil que todas las comunidades que desearan contar con sistemas de medición normalizados tuvieran que mandar representantes a la Urbs con el encargo de copiar los originales custodiados en el Capitolio o en el templo de Cástor. Ello sería posible en el caso de las capitales provinciales o, en todo caso, de los municipios y colonias más importantes, que mandarían con cierta frecuencia legationes a la capital que podrían ser aprovechadas para llevar esas copias a diferentes comunidades. Por otra parte, las autoridades romanas debieron estar interesadas en la difusión de esos modelos, que facilitarían y potenciarían los intercambios comerciales en los territorios bajo su dominio, como así parece demostrarlo el testimonio transmitido por Casio Dión en el que Augusto aconseja a Mecenas no permitir a las ciudades tener sus propias monedas o sistemas de pesos y medidas (Cass. Dio 52, 30, 9) ${ }^{20}$.

La primera posibilidad que podría barajarse, es que en determinadas ciudades provinciales existieran juegos de pesos y medidas, realizados conforme a los estándares de los originales conservados en el Capitolio o el templo de Cástor, para que las ciudades vecinas pudieran tener así un fácil acceso a estos sistemas de medición. Esta hipótesis podría explicar, junto con las variaciones que pudo experimentar la libra romana a lo largo del tiempo, las desviaciones de peso halladas en los pondera descubiertos en el Imperio romano ${ }^{21}$. No obstante, no hemos hallado datos en las fuentes que corroboren esta posibilidad, dado que los epígrafes conservados nunca hacen referencia a modelos ponderarios que no sean los de la capital del Imperio.

En ciertas ocasiones sí aparecen en las fuentes personajes que tuvieron una fuerte vinculación con Roma -generalmente miembros del ordo senatorius o de la administración imperial- y que pudieron facilitar a determinadas comunidades el acceso a unas copias conforme a los estándares custodiados en la Urbs. Este sería el caso de

19 CIL VI, 282. Cfr. J. Bert LotT $(2004,201)$. No obstante, debe tenerse en cuenta que dicha inscripción procede de Roma, por lo que las autoridades tendrían más fácil el acceso directo a los pesos y medidas originales.

${ }^{20}$ Dicho pasaje ha sido interpretado por C. BERRENDONNER $(2009,363)$ como parte del programa de un gobierno idealizado, mejor que una medida llevada a cabo de forma efectiva por el emperador Augusto. Sea como fuere, de ser correcta esta interpretación, indicaría los deseos por parte de la administración central de homogeneizar los pesos y medidas en el Imperio. Diferentes intentos de unificación pudieron ser llevados a cabo en distintas etapas de la historia de Roma, en las que existen un mayor volumen de fuentes que podrían estar indicando precisamente la voluntad de universalizar las medidas romanas. Otra cuestión es, como veremos, si dichas políticas llegaron a buen puerto, dado que tenemos fuentes suficientes como para afirmar que en determinadas comunidades siguieron utilizándose, por ejemplo, medidas de tradición púnica o egipcia.

${ }^{21}$ Numerosos especialistas han tratado de estimar con exactitud el peso de una libra romana sin llegar a un acuerdo comúnmente aceptado. Cfr. CRAWFORD, 1974, 591 s.; quien, finalmente, opta por una cantidad que debió rondar los 324 gr. R. P. DunCan-Jones $(1994,214)$ analizando el conjunto de pesos hallados en Pompeya y Herculano - comunidades que, por otra parte, tendrían más fácil acceso a los originales por su cercanía geográfica con la Urbs - detecta estas mismas variaciones, llegando a la conclusión de que la libra romana debió rondar los $322.8 \mathrm{gr}$. 
L. Domitius Ahenobarbus, procónsul de África en el año 13-12 a.C., que se ocupó de poner una basis para medir trimodios de $\mathrm{sal}^{22}$; de M. Lucceius Torquatus Bassianus (o Cassianus), quien pondera examinata et posita en Calceus Herculis ${ }^{23}$; de Flavius Herodes, procónsul de África en el año 395 d.C., que estableció una mensa para la medición de cereales y vino en $\mathrm{Cuicu}^{24}$ y que, según nos informa otro epígrafe hallado en Thamugadi, constituyó -constitu[it]- medidas para el vino y los cereales ${ }^{25}$; de [- - -]sius Hyginianus cuestor de la provincia de Sicilia que [mensur]as examinavit et in public[o posuit] en Lilybaeum ${ }^{26}$; de D. Simonius Proculus Iulianus, praefectus urbi que, según una inscripción hallada en Neapolis, restableció las medidas en Italia a inicios del s. III d.C. conforme al modelo custodiado en el Capitolio ${ }^{27}$. Incluso tenemos ejemplos en los que aparecen instrumentos para el pesaje o la medición con inscripciones alusivas al emperador, cuya adquisición quizá fuera facilitada por los gobernadores o cualquier alto funcionario de la administración imperial. Este sería, por ejemplo, el caso del decempondio perteneciente a Edeba, en la provincia Tarraconensis $(H E p 14,363)$ y del que es posible encontrar otros paralelos, aunque anepigráficos, en la propia Hispania ${ }^{28}$.

${ }^{22}$ CIL VIII, $1180=14310$. Sobre L. Domitius Ahenobarbus, PIR ${ }^{2}$ D 128. Sabemos, por las fuentes literarias, que las cercanías de Utica, donde se halló la inscripción, debieron ser ricas en sal (Caes. civ. 2, 37, 5; Plin. nat. 31, 81). En la propia Utica existe otro testimonio epigráfico que documenta trimodios para la medición (CIL VIII, 25389). El uso de este tipo de múltiplos debió ser relativamente frecuente en época romana. $C f r$., por ejemplo, para el tricongio, Plin, nat. 14, 144.

${ }^{23} A E 1941,156=1980,954$. Sobre el personaje, que llegó a ser cónsul designatus en 167-169 d.C., véase PIR L 363. Antes de desempeñar su consulado, Torquatus fue legatus de la legio III Augusta en Lambaesis, puesto de gran importancia en el norte de África. Reparemos, además, en que tras la creación de la provincia de Numidia, a finales del s. II d.C., el legado desempeñaría las funciones de gobernador. Obviamente nuestro personaje hubo de tener fuertes relaciones con las comunidades de la futura Numidia como demuestran los hallazgos epigráficos, entre los que destaca su nombramiento como patrono de Thamugadi $(A E$ 1968, 647). Finalmente, no resulta extraño que los legati de las legiones se responsabilizaran de constituir pesos según los estándares romanos, como veremos a continuación.

${ }^{24}$ ILAlg. II.3, 8023. Sobre el personaje, véase PLRE I, 426-427. N. TRAN (2008, 344), retomando el argumento de C. LePelley $(1981,408)$, piensa que este acto tendría seguramente motivaciones fiscales, en especial por su posible relación con las disposiciones recogidas en C. Th. XII, 6, 21 (386 d.C.), donde se mencionan las mismas unidades e instrumentos de medida que la inscripción que nos ocupa, aunque en el contexto de la política fiscal imperial. Finalmente, C. Berrendonner $(2009,369$ s.) ha vinculado recientemente la acción de estos gobernadores en materia de pesos y medidas con motivaciones fiscales.

${ }^{25}$ AE 1954, 155.

${ }^{26}$ CIL X, 7235. Sobre este personaje, véase $P I R^{2} \mathrm{H} 237$.

${ }^{27}$ ILS 8627. Sobre el personaje, PIR S, 529. Como vimos, una acción parecida fue tomada por otro prafectus urbi, Vettius Agorius Praetextatus, ciento cincuenta años después: ponderaque per regiones instituit universas, cum aviditati multorum ex libidine trutinas conponentium occurri nequiret (Amm. $27,9,10)$.

28 Se conservan otros dos decempondios anepigráficos hallados en Huete (Cuenca) y en Arucci/ Turobriga, en este último caso en el derrumbe de una estancia del noreste del foro (CAMPOS CARRASCO; Bermejo MelÉndez, 2007, 260-261). Junto a esta pieza apareció también el contrapeso de una statera (aequipondium) y, en el entorno de la estancia, una plomada (perpendiculum). Estos hallazgos y el hecho de que la estancia pudiera estar también abierta al ¿macellum? de la localidad, ha hecho que recientemente se haya interpretado como una posible officina ponderaria (BERMEJo MELÉNDEZ; CAMPOS CARrasco, 2009, 187-198). Algunos ejemplos de instrumentos para el pesaje en la Bética fueron publicados por F. ChAVES TRISTÁN $(1982,219-222)$ y, más recientemente, para Hispania en general, por F. Chaves Tristán y R. Pliego Vázquez (2007, 237-250). 
También conocemos que las legiones romanas portaron juegos de pesos estandarizados que pudieron estar relacionados con la actividad monetaria y comercial desplegada entorno a los asentamientos castrenses de la época y que directa o indirectamente pudieron influir en la adopción del sistema ponderal romano por parte de comunidades que no tenían contacto directo con la Urbs, especialmente en las provincias limítrofes del Imperio ${ }^{29}$. Este sería el caso de los pondera pertenecientes a la Legio I Italica (CIL III, 784) hallados en Ruscitza (Moesia Inferior), que L. Iulius Lucilianus, legatus Augusti, se ocupó de examinar y signar - pondera examinata sig(navit)-; o de los de la legio V Macedonica Pia Fidelis (CIL III, 12645) hallados en Potaissa (Dacia), posiblemente donados por Val(erius) Sabinus optio leg(ionis) de esa misma unidad ${ }^{30}$.

No obstante tampoco podemos descartar que la extensión del sistema de pesos y medidas romanas por el Imperio se efectuase a partir del duplicado de originales que fueron recepcionados por las ciudades y que sí obedecían a los cánones conservados en el Capitolio o en el templo de Cástor. Ello podría deducirse de la lectura de una inscripción recientemente publicada y que quizás podría leerse como sigue: In $\mathrm{Se}$ gestica // R(ecepi) m(ensuram) I / f(eci) II (AE 2007, 1143).

Otro proceso mediante el cual pudieron difundirse los estándares romanos de pesos y medidas fue a través de las cecas imperiales ${ }^{31}$, que quizás funcionaron como centros autorizados para la fabricación de este tipo de muestras y que pudieron contar con duplicados realizados directamente a partir de los conservados en el Capitolio, por lo que, a su vez, aunque indirectamente, se convertirían en originales para la reproducción de copias.

Una buena oportunidad para comprobar cómo las autoridades romanas intentaron estandarizar las unidades de pesos y medidas por todo el Imperio y los métodos que se emplearon en este fin es el estudio del denominado modius de Ponte Puñide (A Coruña, España; $A E 1915,75)^{32}$. Se trata de un vaso cilíndrico para la medida de áridos que porta una inscripción en forma de doble collar en su parte superior ${ }^{33}$, que puede ser datada en el 369 o 370 d.C. Dicha pieza es muy interesante porque la ley a la que se hace referencia-modii l(ex) iuxta ...- puede ser puesta en relación con disposicio-

${ }_{29}$ No olvidemos que el papel de las legiones en el proceso de romanización es un hecho bien conocido y generalmente aceptado en la actualidad. Sobre el tema, cuya bibliografía es abundantísima, véase por ejemplo, Y. Le BoHEC $(2000,231-252)$. Por otra parte, la mayoría de los pondera con la fórmula exactum ad Castoris han sido hallados en la zona del limes, por lo que han sido relacionados con la actividad de los mercatores que aprovisionaban al ejército. No obstante, como puso de relevancia C. Berrendonner $(2009,369)$, esas series se caracterizan por ser subdivisiones "très fines" de la libra, por lo que pudieron ser empleadas para pesar metales preciosos o monedas, quizás para el pago de la soldada. No olvidemos la relación que tuvo el templo de Cástor en Roma con este tipo de actividades (vid. supra).

30 T. Sarnowski pone en relación los pondera de estas legiones, datables entre 209 y 211 d.C. con una posible reorganización de la annona militar bajo los Severos. Cfr. comentario en $A E$ 1994, 1529.

${ }^{31}$ C. CORTI $(2001 b, 204)$.

32 Sobre esta pieza y la inscripción, consúltese el trabajo de R. DE UREÑA (1915, 485-507), al que remitimos para ampliar la información que en seguida expondremos.

${ }^{33}$ Modii l(ex) iuxta sacram iussio[n]em ddd(ominorum) nnn(ostrorum) Valentiniani Valent( $\left.i\right)_{s}$ et Gratiani invictissimorum / principum iubente Mario Artemio v(iro) c(larissimo) ag(ente) vic(ariam) p(raefecturam) cur(antibus) Potamio et Quentiano(!) principalibus. 
nes análogas emanadas desde el poder central y que pudieron tener vigencia en todo el Imperio. Como ya vimos, el prafectus urbi Vettius Agorius Praetextatus restableció los pesos y medidas existentes en Roma atendiendo a las órdenes decretadas por el emperador Valentiniano (Amm. 27, 9, 10). Dicha constitución imperial no se nos ha transmitido, pero alguna de las medidas allí expuestas pueden ser conocidas gracias a otros testimonios más tardíos. En concreto el lexicógrafo Suidas (s. X) nos informa de que en Constantinopla existía, junto a un hórreo, un modius público para comprobar que las ventas de grano fueran exactas y de que esta medida fue establecida por Valentiniano, quien ordenó, además, que los doce modios de trigo fueran vendidos por un sueldo. Y a quien no respetase la norma le sería cortada la mano derecha. Por su parte, G. Codino (s. XV), quien entre otras fuentes utilizó el Lexicon de Suidas, añade que el modius formaba parte de un monumento en el que existía un reloj y dos manos figuradas en bronce, para recordar a los posibles infractores la amputación de los miembros que sufrió un mercader que contravino la ley ${ }^{34}$.

Algunos años más tarde, sabemos que Graciano, Valentiniano II y Teodosio I establecieron la obligatoriedad de exponer públicamente los pesos y medidas para evitar el fraude en el cobro de tributos (C. Th. XII, 6, 19; de 3 de octubre del 383 d.C.); y tres años después Valentiniano II, Teodosio I y Arcadio reprodujeron y ampliaron esas mismas disposiciones, advertiendo que los preceptores de tributos que manipularan esas medidas estarían contraviniendo la ley y se enfrentarían a la correspondiente pena (C. Th. XII, 6, 21 y C. Iust. X, 72, 9; de 28 de noviembre del 386 d.C.). Además, estos mismos gobernantes decretaron la adopción de pesos y medidas estandarizados por parte de todas las ciudades, responsabilizando al prefecto del pretorio de este procedimiento (C. Iust. X, 70, 9).

Pues bien, es más que probable que la $l(e x)$ a la que se hace referencia en el modio de Ponte Puñide esté en relación con las medidas que acabamos de comentar y, concretamente, como también podría deducirse de la inscripción, el objetivo de la misma sea remediar los abusos y rebajar la presión fiscal existente en la época. De hecho, el documento nos informa acerca del procedimiento seguido para la aplicación de esas medidas, que partieron de los emperadores de la época y fueron extendiéndose por todo el territorio gracias a la administración imperial. En nuestro caso, fue Marius Artemius, vicarius Hispaniarum entre el 369 y 370 d.C., quien ordenó el cumplimiento de las directrices aprobadas por Valentiniano, Valente y Graciano, siendo en última instancia los principales Potamius y Quentianus los encargados de establecer las medidas exactas para la recaudación de impuestos. Como vemos, el interés de este documento es que se puede vislumbrar perfectamente el proceso seguido para la instauración de pesos y medidas conforme a la legislación imperial. Aunque tales hechos pueden ser contextualizados en el último tercio del s. IV d.C., no hay razones para descartar que estos procedimientos funcionaran desde mucho antes ${ }^{35}$.

${ }^{34}$ Sobre estos testimonios, véase R. De UreÑa (1915, 495-497).

${ }^{35}$ La reciente aparición en Bitinia-Ponto de una serie de pesos con la titulatura imperial, el nombre del gobernador de la provincia y el del agoranomos de la comunidad no haría sino confirmar un modelo de administración preconcebido y descentralizado en la difusión y estandarización de este sistema. Sobre estos documentos, véase P. Weiss (2005, 405-442); R. HaEnsch y P. WeIss (2005, 443-498 y 2007, 183-218). 
La legislación analizada anteriormente parece demostrar que la administración central trató de unificar cánones y de generalizar la legislación referente a pesos y medidas por todo el Imperio, intentando crear un mercado universal que facilitara los intercambios comerciales en todo el mundo romano ${ }^{36}$. Pese a que las fuentes que acabamos de comentar corresponden a finales del s. IV d.C. y pueden explicarse en parte por la preocupación de los emperadores de la época por controlar y evitar el fraude en la percepción de impuestos, lo cierto es que el deseo de normalizar y generalizar los pesos y medidas romanos es muy anterior e incluso podemos pensar que en ocasiones pudo partir de las autoridades locales. Así parece demostrarlo algunos epígrafes entre los que destaca la famosa mensa descubierta en Pompeya (CIL X, 793) que, en origen, contendría medidas y una inscripción de época osca. Este sistema fue adecuado a la normativa romana alrededor del 20-15 a.C. por los duunviros $A$. Clodius Flaccus y N. Arcaeus Arellianus Caledus, como parece indicar la fórmula "mensuras exaequandas" ${ }^{37}$. En todo caso, ambos magistrados actuaron ex decreto decurionum, por lo que debemos pensar que el asunto fue debatido y aprobado en el senado local.

Es más, la adopción del sistema de pesos y medidas se difundió más allá de los municipios y colonias del Imperio romano, como demuestran determinados testimonios que documentan su uso en entidades jurídico-administrativas menores como los pagi, en los que también existieron ediles, ya sea como reflejo e imitación del sistema político romano o como magistrados "delegados" de las comunidades a las que estaban adscritos estos pagi. Así, por ejemplo, un aed(ilis) $p a<g>i$ Bag(- - -) pudo destruir (aere fracto) unas medidas falsas ${ }^{38}$ (CIL XI, 1377). Igualmente, sabemos que dos personajes de la gens Sulmonia reconstruyeron el ponderarium del pagus Interprominus que posiblemente había sido destruido por uno de los terremotos que afectó a la península Itálica durante el s. II d.C. (CIL IX, 3046).

No obstante, todo ello no impidió que en determinadas comunidades se continuaran utilizando medidas no romanas, como demuestra una de las mensae halladas en Lepcis Magna que presenta medidas de longitud de tradición púnica, egipcia y grecoromana ${ }^{39}$; o por otra mensa recuperada en Thibilis en la que aparecen medidas como el codo egipcio, un codo inferior y el pie romano destinadas seguramente al control de la construcción ${ }^{40}$.

36 Este proceso de unificación normativa que iba de Roma a los municipios pasando por la administración provincial debió de ser relativamente frecuente. Así, por ejemplo, debió darse en el caso del comercio de esclavos y bestias difundiendo por todo el Imperio el corpus legislativo contenido en el edicto de los ediles curules, como muy bien observó F. SERrao (2000, 64-65).

37 Otras inscripciones que pueden estar haciendo referencia a la adopción o a la normalización del sistema de pesos y medidas romano: CIL X, 6017 (pondera et metra exaequarunt); AE 1906, 26 (mensuras exaequ[a]tas). Según M. CÉBEILlAC-GERVASONI (1990, 709), la primera de estas inscripciones respondería al momento en el que a los duunviros de Minturnae se les encargó cambiar el sistema de pesos y medidas de la colonia, hacia mediados del s. I a.C.

38 En este sentido, S. M. Marengo $(1999,83)$ puso en relación, creemos que acertadamente, la expresión aere fracto con ex mensuris iniquis, que también aparece asociada a testimonios epigráficos en relación con los pesos y medidas y que será comentada más ampliamente infra.

39 De Ruyt, 1983, 104.

40 Cfr. Tran, 2008, 338-339. Según P. Barresi $(1994,483)$ se trataría más bien de dos codos de tradición púnica - un codo structorius usado para la construcción y otro fabrilis utilizado por los maestros y artesanos, de 0.516 y $0.509 \mathrm{~m}$. respectivamente- $\mathrm{y}$ un pie romano de $0.296 \mathrm{~m}$. 
Como venimos apreciando, las fuentes históricas, relativamente escasas para el estudio de los pesos y medidas en la capital del Imperio son algo más abundantes si acudimos al registro documental de las colonias y municipios del Imperio romano. En primer lugar cabe destacar que contamos con dos testimonios literarios que relacionan la edilidad con la administración de pesos y medidas fuera de la Urbs a inicios de la primera mitad del s. I d.C. y en los primeros años del s. II d.C. El primero de ellos nos lo proporciona Persio $(1,130)$, quien satiriza sobre la necedad comparándola con la actuación de un edil que se jacta de su poder por destruir unas medidas falsas en Arezzo (Arretium, Regio VII); mientras que Juvenal (10, 100-101) habla de la potestad que tenían estos mismos magistrados en Ulubra ${ }^{41}$, donde podían destruir los recipientes que no se adecuaran a la capacidad legal. Paralelamente, ya comprobamos cómo el Digesto $(19,2,13,8)$ también recoge la potestad de los ediles de destruir medidas falsas y que, a partir de Adriano, el castigo por el uso de las mismas era el confinamiento a una isla (Dig. 47, 11, 6, 2 y 48, 10, 32, 1). Además, el testimonio de Juvenal es interesante porque muestra de forma explícita que los ediles tenían derecho de jurisdicción (de mensura ius dicere), por lo que podrían iniciar procesos judiciales contra los que contravenieran la ley $\mathrm{e}^{42}$.

Dicha información se ve confirmada en el capítulo XIX de la lex Irnitana, en el que aparecen desarrolladas las competencias de los ediles del municipio bético. Concretamente, en la parte que más nos interesa aquí: ....annonam aedes sacras loca sacra religiosa oppidum vias vicos cloacas bal[i]nea macellum pondera mensuras exigendi aequandi vigilias cum res desiderabit exigendi..${ }^{43}$ No obstante, en los reglamentos municipales conservados de época flavia, apenas conservamos otras alusiones en relación a la cura annonae local en general y al control de los pesos y medidas en particular. De hecho únicamente el cap. LXXV de la lex Irnitana contiene disposiciones en relación a la annona, prohibiendo el acaparamiento o la retirada de productos con fines especulativos, todo ello bajo pena de 10.000 sestercios $^{44}$. Sin embargo, ello no quiere decir que no existiera una normativa más específica que reglamentase el uso de los pesos y medidas en los estatutos municipales. De hecho, una inscripción de Compsa nos informa de que el cuatorviro C. Umbrius Eudrastus Fortunatus donó mensurae "lege civitatis proprio sumptu" (CIL IX, 980) $)^{45}$. Por desgracia, descocemos

${ }^{41}$ Se desconoce la localización de Ulubra, que también aparece en la obra de Horacio (epod. I, 11, 29) y que debió ser conocida por ser un lugar aislado y desierto.

${ }_{42}$ Cfr. M. KurYlowicz (2000, 446-447).

43 Dichas competencias debieron recogerse también en otros dos fragmentos broncíneos de procedencia desconocida que se corresponderían con el cap. XIX de la lex Irnitana y que pertenecieron a sendos municipios, ambos ignotos, (HEp 9, 619 y 624; $c f r$. A. CABALlos y F. FernándEZ, 2002, 263 s. y $n^{\circ}$ II; y 267 s. y n ${ }^{\circ}$ VII, respectivamente). Sobre la administración de la cura annonae en el ámbito municipal y sobre este capítulo de la lex del municipio de Irni, aunque de manera muy general, véase W. LANGHAMMER $(1973,150-151)$ y F. LAMBERTI $(1993,64-67)$, respectivamente.

${ }^{44}$ Es muy posible que dicha rúbrica tenga relación con la lex Iulia de annona (c. 18 a.C.). Sobre la misma, pueden consultarse también las disposiciones recogidas en el Digesto $(48,12)$.

${ }^{45}$ Sobre esta inscripción, véase E. FolCando (1996, 303-308). Recientemente E. H. Bispham (2007, 216 , n. 50) especuló con la posibilidad de que dicho personaje actuara en virtud del desempeño del cuatorvirato relacionándolo con la pareja de magistrados con poderes edilicios. No obstante, debemos advertir de que no se trata de un acto oficial vinculado a las competencias de un magistrado, sino de 
hasta qué punto la ley de ese municipio reguló la adopción y el uso de pesos y medidas por parte de sus ciudadanos.

En relación al objeto de análisis de nuestro trabajo, es de enorme interés el cipo funerario de L. Severius Severinus (CIL XII, 3273), edil de la colonia Augusta Nemausus que contiene varios relieves en alusión a la potestas desempeñada por este magistrado durante el ejercicio de su cargo ${ }^{46}$. En la parte superior del campo epigráfico se esculpió una balanza con su anilla de suspensión, un platillo circular y dos o tres pesos graduados en tamaño. Parece bastante probable que esta iconografía esté directamente relacionada con el control de pesos y medidas y quizás, por extensión, a los poderes desarrollados por los ediles en materia annonaria.

Parece por lo tanto fuera de toda duda que, en el ámbito local, los ediles fueron los encargados ordinariamente de velar por el uso de unos pesos y medidas adecuados a los estándares romanos, incluso cuando en la Urbs la alta supervisión de éstos era desempeñada por otros magistrados como los praefecti urbi. Todo ello parece encontrar confirmación en numerosas inscripciones halladas en otras tantas comunidades por todo el Imperio, si bien dicha documentación puede estar vinculada a actos munificentes de los que no se debe deducir necesariamente el desempeño de unas competencias como las que estamos aquí analizando. De hecho, los ediles no fueron los únicos magistrados o responsables de la administración que donaron o se encargaron de dotar a sus respectivas comunidades de juegos de pesos o medidas, generalmente ponderaria y mensae para la comprobación de diferentes medidas. Así, encontramos ediles vinculados a este tipo de actos en Auzia (CIL VIII, 9062 y 9063), Beneventum (CIL IX, 1656), Histonium (CIL IX, 2854), Philippi (AE 1935, 49), Pisaurum (CIL XI, 6375), Thamugadi (AE 1906, 26), Thibilis (AE 1909, 154), Tiaret (AE 1912, 156) y Tusculum (CIL XIV, 2625). A este conjunto podríamos añadir otros dos personajes que no desempeñaron la edilidad, pero sí asumieron la aedilicia potestas en Brixia (CIL V, 4468) y Cartenna (CIL VIII, 9666), quizás, precisamente, con el objetivo de restaurar o dotar a la comunidad de un sistema de pesos y medidas adecuado, lo que no haría sino confirmar que eran los ediles los encargados de estas competencias en el ámbito municipal.

No obstante, existen otros magistrados que participaron activamente en actos como los que venimos comentando: un cuatorviro en Compsa (CIL IX, 980); duunviros en Herculaneum (CIL X, 1453), Minturnae (CIL X, 6017), Nola (CIL X, 1276) o Pompei (CIL X, 793); un q(uin)q(uennalis) aedil(is) en Lambaesis (CIL VIII, 3294); Magg(istri) en Lamberidi (AE 1922, 12); un curator rei publicae de Neapolis (AE 1979, 168); los principales de Ponte Puñide ( $A E$ 1915, 75); o personajes que desarrollaron un amplio cursus honorum en sus respectivas comunidades cívicas ${ }^{47}$. Incluso libertos pertenecientes a las oligarquías locales también participaron en la donación de pesos y medidas, como por ejemplo un octoviro augustal de Falerio (AE 1922, 89); un augustal de Minturnae (AE 1982, 155); varios augustales de una comunidad

una evergesía. A este respecto, como veremos infra, tampoco son extrañas las donaciones de sistemas ponderales o de medición efectuadas por duunviros en otras comunidades cívicas.

${ }^{46}$ Sobre el documento, véase el interesante comentario de L. Lamolne (2003-06, 3-7 y 2009, 276280).

${ }^{47}$ CIL XIV, 375 y 376; ILAlg II.3, 7929 = 7930; y, seguramente, CIL V, 6771 y ILTG, 362. 
itálica ignota (CIL VI, 29703) 48 ; o un magister Herculaneus (CIL XIV, 3687 y 3688; Inscr. It. IV.1, 223). Finalmente, cabe destacar la donación de un ponderarium e instrumentos de medición por parte de un importante primipilar de Tuficum (CIL XI, $5695)^{49}$. En otros casos, desconocemos el estatus socio-político del donante, ya sea porque la inscripción nos ha llegado en estado fragmentado o, simplemente, porque se omite esa información: CIL V, 683950; IX, 3046; X, 5797 y 7598; XIV, 423; $A E$ 1988, 556; 1999, 1120.

Como podemos apreciar, pese a la relativa diversidad socio-política de los personajes que donaron o dotaron a sus respectivas comunidades de instrumentos o de infraestructuras relacionadas con la medición y ponderación de productos, los ediles son el grupo que parece más involucrado en este tipo de acciones, seguramente porque durante su ejercicio de la magistratura tendrían oportunidad de comprobar de primera mano las necesidades de sus municipios en torno al control de pesos y medidas y los posibles abusos que se podrían cometer si no se contaba con unos estándares e infraestructuras adecuados. De hecho, los datos que acabamos de exponer adquieren todavía más importancia si reparamos en el hecho de que los ediles rara vez protagonizaron actos munificentes que, en general, se realizaron cuando los miembros de los ordines decurionum conseguían acceder a la máxima magistratura o sacerdocio local ${ }^{51}$. Por otra parte, no podemos negar que la vigilancia de los pesos y medidas en el ámbito local no fue monopolio de los ediles ${ }^{52}$. Quizás el ejemplo más claro sea un decreto decurional mediante el que sabemos que un padre y un hijo, ambos duunviros de Herculaneum, donaron, entre otras cosas, unos pondera, seguramente en su afán de corregir las faltas de estos instrumentos (vitieis ponderum occurrerint) y se comprometieron, quizás viéndose forzados por el ordo decurionum y ante su

48 Pese a que la inscripción fue hallada en Roma, seguramente fue transportada allí desde alguna ciudad italiana durante la Edad Media (AshBy, 1906, 54).

49 Se trata de C. Caesius Silvester quien, tras una destacada carrera militar, se debió retirar en Tuficum, posiblemente su ciudad natal, donde fue nombrado patrono de la misma y desarrolló una importante actividad evergética en la primera mitad del s. II d.C. De este personaje se conocen más de una docena de inscripciones en dicha comunidad (CIL XI, 5687; 5694-5700; 8051-8054).

${ }^{50}$ Ciertos autores entienden que se trataría realmente de un legado testamentario, pero la relectura de L. GASPERINI $(1991,720)$, especialmente del inicio de la inscripción, [- - exa?]gium addito pondere p(ecunia) s(ua) posuit, parece vincularla con un acto evergético en el que se donaría, bien un juego de pesas, bien un ponderarium. En el mismo sentido, $c f r$. R. SCUDERI (2008, 250, n. 72).

51 Así, por ejemplo, véase J. F. Rodríguez Neila y E. Melchor (2000, 167 ss.) para la Bética y Lusitania. Paralelamente, piénsese que de los más de setecientos edificios conocidos en África que fueron reparados o donados en su totalidad o en parte por munificentes ciudadanos, sólo nueve fueron financiados únicamente por ediles (WILKINS, 1988, 218).

52 De hecho, como estamos comprobando, si nos atenemos a la información que nos aporta la documentación epigráfica, las competencias de los magistrados municipales no responden al esquematismo que en muchas ocasiones deja entrever la historiografía. Incluso fuera del ámbito de análisis que ocupa estas líneas, pero dentro de la llamada cura annonae, existen otros ejemplos que nos llevan sin dudas a la conclusión que estamos exponiendo. Así, podemos poner como ejemplo una reciente inscripción hallada en la Bética que documenta una dedicación votiva realizada por los duunviros de una comunidad "ex multis pistorum" (S. Ordóñez; J. C. SAQUETE, 2009, 197-204), cuando por otros testimonios, entre los que destaca un famosísimo pasaje del Satiricón de Petronio (Satyr. 44), parecería a todas luces que esas labores entrarían dentro del ámbito de competencias de los ediles. 
reelección para el duunvirato, a cuidar de los mismos a perpetuidad (CIL X, 1453) $)^{53}$. La inscripción es interesante, además, porque a estos magistrados se les adjudica un esclavo para la cura de los pondera, por lo que constituye uno de los pocos ejemplos en los que aparece personal subalterno asociado a la administración de pesos y medidas en el ámbito local. Igualmente, una inscripción funeraria procedente de Teanum Apulum (CIL IX, 706) parece documentar a dos ponder(arii), seguramente empleados especializados en alguna de las tareas diarias relacionadas con el uso y la administración de los pesos en el ámbito local ${ }^{54}$. Finalmente, podemos citar la existencia de un "IIIIvir macelli" en Lepcis Magna (IRT, 294 = AE 2003, 1902) que podría ser interpretado tanto como personal perteneciente al equipo de subalternos de los ediles, como magistrados encargados de la vigilancia del mercado ${ }^{55}$.

Mención aparte merece el caso de Ostia por la vinculación que tuvo este puerto con el abastecimiento de la annona de la capital ${ }^{56}$. En efecto, existen varios documentos epigráficos que documentan un amplio equipo de personal especializado que además contó con sus propias infraestructuras -templo y aula de los mensores; regio I, insula XIX-y que debió depender, en mayor o menor medida, de la administración imperia ${ }^{57}$. Paralelamente, las autoridades coloniales debieron controlar los pesos y medidas depositadas, al menos, en el macellum y el forum vinarium de la comunidad y cuya existencia está testimoniada en varios epígrafes que nos informan de la donación por varios personajes de estos instrumentos de medición ${ }^{58}$. De entre ellos destacan los referentes a P. Lucilii Gamalae (CIL XIV, 375 y 376), dos personajes homónimos que debieron pertenecer a la misma familia y que, en distintos momen-

${ }^{53}$ Cfr. R. K. SHERK (1970, 31 s., 79).

54 Apoya esta lectura, entre otros E. Michon $(1969,548)$ y más recientemente M. Chelotti y G. Mennella (1994, 164, n. 37).

55 El IIIIvir macelli de Lepcis Magna aparece realizando una dedicación a Liber Pater ex multis. Dado que dicho personaje está haciendo uso de la potestas de la que generalmente gozaron los ediles, parece a todas luces que se trataría de un magistrado. De hecho se ha pensado que este personaje sería más bien un IIIIvir aedilicia potestate (cfr., por ejemplo, Di VITA-ÉvRARD, 2002-03, 300-304). Sin embargo la inscripción se data en el s. I d.C. y sabemos que en esas mismas fechas Lepcis Magna contaba con ediles que también tenían un activo papel en el macellum de la comunidad, como demuestra la donación por parte de dos de estos magistrados de quince o dieciséis mensae que debieron ocupar los espacios de los intercolumnios de los pórticos que rodeaban las dos tholoi del mercado (IRT, 294g). Podría pensarse así que los IIIIviri macelli fueran personal subalterno vinculado a los ediles, aunque el hecho de que pudieran imponer multas creemos que aboga en contra de esa posibilidad.

56 Sobre este particular, véase C. CORTi (2001a, 159-161).

57 Así, por ejemplo, sabemos de la existencia de un corpus mensorum frumentariorum (CIL XIV, 172), de los mensores frumentarii Cereris Augustae (CIL XIV, 409), del corpus mensorum frumentariorum adiutorum et acceptorum (CIL XIV, 154), de un corpus mensorum frumentariorum adiutorum (CIL XIV, 4140) o de un corpus mensorum adiutorum (CIL XIV, 2). Es posible que todos estos corpora formaran parte de una misma corporación dividida en secciones o decuriae y que tuvieran su propia organización interna, como demuestra la existencia, por ejemplo, de quinquenales del corpus mensorum frumentariorum nauticariorum (CIL XIV, 289). Sobre estas corporaciones y los miembros de la administración imperial de Ostia en relación a la annona, véase J. P. WALtzing (1896, 58 ss.) y N. TrAN (2006, 242 ss.).

58 CIL XIV, 375 y 376 (dos destacados personajes con un amplio cursus honorum local); CIL XIV, 423 (un liberto); CIL XIV, 4719 (un personaje de rango senatorial). Sobre las mensae halladas en Ostia, consúltese G. Darrou (1993, 323). 
tos, donaron pondera ad macellum. Además, Gamala iunior añadió mensuras ad forum vinarium ${ }^{59}$. En definitiva, el ejemplo de Ostia nos permite comprobar que en una misma comunidad pudo convivir personal de distintas administraciones que estuviese involucrado en el control de pesos y medidas con objetivos y necesidades muy concretos. Igualmente, podemos afirmar que en colonias o municipios importantes existieron diferentes juegos de pesos y medidas custodiados en distintos lugares, tal y como hemos analizado para el caso de la Urbs.

Como acabamos de exponer, un buen número de las inscripciones que se nos han conservado sobre la donación de instrumentos de medición responden a la acción munificente de ciudadanos pertenecientes a las oligarquías locales. En otras ocasiones, sin embargo, miembros del ordo decurionum debieron verse más o menos forzados a destinar parte de su riqueza en pro de la comunidad. Este sería probablemente el caso de L. Cosinius Primus, un notable que desarrolló un completo cursus honorum en Cuicul y que financió un macellum cum columnis et [- - et] statuis et ponderario et tholo pro honore flamonii y que taxaverat multiplicata pecunia ${ }^{60}$ (ILAlg. II.3, 7929).

No obstante en ciertos casos testimoniamos que las instituciones debieron usar fondos públicos para la dotación de este tipo de infraestructuras e instrumentos de medición en sus respectivas comunidades. Así la civitas Galitana financió un aedes curialem Concordiae et tabularium et ponderarium a solo pecunia publica fecit et dedicavit (CIL VIII, $757=12221)$; dos duunviros de Pompei adecuaron las medidas de época osca a las romanas ex dec(urionum) decr(eto) (CIL X, 793); en el noroeste de Hispania dos principales se encargaron de adecuar los modios según la lex ( $A E$ 1915, 75); finalmente, un edil de Thibilis se encargó de establecer mensuras structorias et fabriles (ILAlg. II.2, 4705). También debemos adscribir -al menos en buena parte- a la financiación pública la construcción por parte de la res publica coloniae Septimiae Aureliae Auziensium de un macellum cum porticibus et ponderibus omnibusque ornamentis que fue pagado, además, ex sportulis decurionum (CIL VIII, 9062 y 9063). A esa cantidad se le sumó las summae honorariae aportadas por los ediles $C$. Aufidius Victorinus y [-] Iuventius Karus ${ }^{61}$.

59 La bibliografía sobre los documentos epigráficos que estamos comentando es ingente y, fundamentalmente, gira en torno a la identificación del bellum navale citado en CIL XIV, 375. Ello ha servido a numerosos especialistas para establecer diferentes dataciones para esta inscripción, que oscilarían entre época silana y el segundo triunvirato. No obstante, tampoco debemos olvidar que una parte de la historiografía interpreta esa expresión con la donación, por parte de Gamala senior de una naumachia, lo que invalidaría todas las hipótesis de establecer una cronología a través de la identificación del bellum navale con cualquiera de los conflictos marítimos de Roma en el s. I a.C. Todo ello sin olvidar que la inscripción pudo pertenecer a un monumento funerario, lo cual crearía un desfase cronológico entre la datación del cursus honorum de este personaje y el momento de la erección del epígrafe, que sería, por lo tanto, posterior. En este sentido, véase O. SALOMIES (2003, 133-157), quien además realiza una completa puesta al día de la bibliografía precedente y, recientemente, M. CÉBEILlaC-Gervasoni; M. L. CAldelli; F. Zevi, (2010, 99 ss., nº 11.1).

${ }^{60}$ Sobre el significado de la taxatio en este ejemplo concreto y su diferencia con la summa honoraria y las pollicitationes, véase C. BRIAND-Ponsart (2008, 112-115, especialmente p. 114).

${ }^{61}$ Con casi total seguridad, el dinero de las sportulae que destinaron los decuriones a la financiación de estas infraestructuras no tuvieron un origen público. A. U. Stylow y H. Gimeno (2001, 108, n. 48) se decantan porque este tipo de donaciones serían más bien privadas, teniendo origen, por ejemplo, en la erección de una estatua a la que el honrado añadiría la donación de sportulae que podrían beneficiar 
En otras ocasiones encontramos a magistrados locales o funcionarios de la administración interviniendo en el establecimiento de pesos y medidas sin que por ello podamos deducir de la documentación epigráfica que estuviesen actuando como evergetas. Este sería el caso del curator rei publicae Nolanorum Fl. Lucretius Publianus que stateriam cum ponderibus iustis deferendam curavit $(A E 1979,168)^{62}$. Lo más probable es que Publianus estuviera cumpliendo esta tarea como máxima autoridad local y, seguramente, la statera con sus pesos fueron financiados con dinero público.

Es posible que incluso en determinados casos, algunos de los comerciantes beneficiados por la instauración de unos nuevos juegos de pesos o medidas financiaran parte de estos instrumentos, como quizás pueda deducirse de un testimonio epigráfico de Histonium (CIL IX, 2854) ${ }^{63}$.

Mención aparte merece la fórmula ex iniquitatibus u otras similares que en ciertas ocasiones aparecen asociadas a inscripciones que documentan la donación o constitución de pesos y medidas estandarizados en algunas comunidades cívicas romanas ${ }^{64}$. Generalmente, la historiografía ha optado por explicar esta expresión de dos formas, bien el dinero con el que se realizaron los instrumentos de medición provenía de las multas que imponían los ediles, bien se costearon con las incautaciones de pesos y medidas falsas que estos mismos magistrados realizaron en sus respectivos municipios o colonias ${ }^{65}$. Sobre esta cuestión resulta de especial interés una inscripción latina hallada en Philippi $(A E$ 1935, 49) que nos informa de que los ediles emplearon cuarenta y cuatro libras de bronce en la dotación a su comunidad de unos nuevos pesos y medidas, seguramente procedentes de incautaciones de medidas falsas (ex mensuris iniquis aeris $p$ (ondo) XXXXIIII). No obstante, ese mismo documento nos informa que los magistrados realizaron la acción $d(e) s(u a)$ p(ecunia). Este hecho,

a determinados sectores de la población más o menos amplios y "puesto que eran donaciones que recibían los decuriones (...) naturalmente podían disponer de ellas a su libre albedrío". No obstante, debemos recordar que existieron celebraciones parecidas, seguramente incluso más fastuosas, como serían epulae, cenae o viscerationes financiadas con dinero público. Sobre las mismas, J. F. RodríGuEz NeILA (2006, 123-142). En cuanto a las summae honorariae, eran pagos de obligado cumplimiento para quienes desempeñaran o fueran elegidos para un cargo público y debieron revertir en las arcas municipales con el fin de financiar gastos públicos, quizás, en origen, ludi reglamentarios, aunque los decuriones preferirían disponer libremente de esas cantidades en metálico para invertirlas según las necesidades de la comunidad (Melchor, 1994, 194 ss.). Por lo tanto, podemos afirmar que al menos parte de las infraestructuras de Auzia fueron financiadas con dinero público.

${ }^{62}$ Como apuntó G. CAmodeca (1979, 232 ss.), el interés de esta inscripción está en el hecho de que es uno de los pocos testimonios en los que aparece un curator asumiendo competencias que durante el Alto Imperio desempeñaron los ediles. La inscripción que nos ocupa se data en el s. IV d.C., aunque no antes del emperador Constantino.

${ }^{63}$ Según una reciente interpretación, parte de los pesos instalados en esta comunidad pudieron ser financados por los [merc]atores o los [pis]tores (cfr. BROEKAERT, 2008, 206).

${ }^{64}$ CIL IX, 2854 "ex metr[etis et ponderib] us iniquis"; CIL XI, 6375 "Ex iniquitatibus mensurarum et ponder(um)"; $A E$ 1935, 49 "ex mensuris iniquis"; AE 1999, 1120 "ex iniqu[itatibus mensurarum et ponderum]"; $\mathrm{y}$, probablemente, CIL XIV, 2625 "mensuras et pondera iniq[ua frangi?] iusserunt [- - -]".

${ }_{65}$ Así, por ejemplo, B. BorghesI $(1865,341-342)$ se decanta por las multas frente a P. Lemerle (1934, 460-461) quien, sin descartar esta opción, prefiere pensar que la financiación procedía de las incautaciones de materiales falsos, aunque, no obstante, no ve razones para que ambas teorías sean incompatibles. Entre la historiografía más reciente, podemos citar a C. De RuYt (1983, 94 y 136) y N. TrAN $(2008,345$, n. 89), defensores de la hipótesis de las incautaciones y de las multas respectivamente. 
que podría parecer a priori contradictorio, no lo es tanto, dado que conocemos ejemplos en otros ámbitos en los que los ediles pudieron disponer del dinero resultante de las multas que ellos mismos habían impuesto ${ }^{66}$. Sea como fuere, es bastante posible que los magistrados tuvieran que actuar, en este como en otros tantos ámbitos, con la aprobación decurional (CIL XI, 6375). Por otra parte, una inscripción de Lilybaeum menciona que un cuestor de Sicilia examinó y puso a disposición pública unas medidas ex mult $[i s]$ (CIL X, 7235).

Por último, no nos gustaría terminar sin dedicar unas líneas al contexto espacial en el que fueron emplazados estos instrumentos de medición, dado que en determinadas ocasiones las fuentes nos permiten conocer el espacio cívico en el que desarrollaron sus competencias los ediles y otros magistrados encargados de la vigilancia de los pesos y medidas. En primer lugar, cabe preguntarse si en las ciudades romanas existió un lugar concreto y más o menos fijo para emplazar este tipo de instrumentos. Efectivamente, existen algunas inscripciones que contienen la mención a ponderaria, entendidos estos como recintos, generalmente pequeños y austeros, en los que se custodiaban y ponían a disposición de los ciudadanos los pesos y medidas públicos verificados por alguna autoridad local, generalmente los ediles ${ }^{67}$. Estos podrían ser los casos de Gales, donde C. Iulius Verus dotó a su comunidad de un aedes curialis, un tabularium y un ponderarium (CIL VIII, 757); de Interpromium, donde los CC. Sulmonii Primus et Fortunatus restituyeron un ponderarium (CIL IX, 3046); de Tiaret, donde el edil Victorinus hizo lo propio sua pecunia $(A E$ 1912, 156); de Tuficum, donde $C$. Caesius Silvester, primipilo que debió retirarse en esa comunidad, financió un ponderarium con sus accesorios (CIL XI, 5695); o de Vercellae, lugar en el que $T$. Sextius Secun [dus] debió realizar una donación similar (CIL V, 6771).

En ocasiones excepcionales conocemos incluso el contexto arqueológico exacto en el que se encontrarían diferentes ponderaria de otras tantas comunidades del Imperio romano. De hecho sabemos que este tipo de estancias solían ocupar un lugar cercano al foro y, en muchas ocasiones, estaban en los aledaños o directamente asociados al macellum o la basilica, seguramente por la relación que pudieron tener este tipo de edificios con la celebración de mercados periódicos en las ciudades romanas ${ }^{68}$. Este

66 Sabemos que en la Urbs el clivus Publicius, fue realizado con el dinero de las multas impuestas durante la edilidad de L. y M. Publicii (Fest. p. 238 y Varro ling. 5, 32). De la misma forma, la lex Tarentina expone que quienes destejaran, demolieran o arruinaran un edificio sin reconstruirlo debidamente serían penalizados con una multa y que los magistrados debían ingresar la mitad de la misma en el erario y la otra mitad gastarla en juegos o ad monumentum suum in publico (lex Tar. 11. 32-38). No hay duda de que esos mismos magistrados podrían optar por emplear ese dinero en un acto en beneficio de la comunidad, tranformando así la acción en un gesto evergético como parece probar de hecho una inscripción procedente de Pompeya: “... ex ea pequnia quod eos e lege in ludos aut in monumento consumere..." (CIL I, $1635=\mathrm{X}, 829)$. Finalmente, S. M. Marengo $(1999,83)$ se decanta porque la gestión de las multas impuestas por los ediles fueron administradas por esos mismos magistrados, sin importar que revirtieran en un arca especial o en el erario municipal.

${ }^{67}$ Este es el significado real que tuvo en época clásica dicha palabra y no "mensa ponderaria" o estelas -o cualquier otro soporte, generalmente pétreo-que contuvieron instrumentos de medición para uso público, de las que nos ocuparemos a continuación (cfr. Michon, 1969, 547).

68 Téngase en cuenta que en los foros romanos, al igual que en las ágoras griegas anteriormente, se pudieron celebrar mercado periódicos antes de la construcción de edificios especializados para el desarrollo de la actividad comercial. De hecho, en el mundo griego y a partir del s. IV a.C., comienzan a 
sería el caso de Cuicul, donde L. Cosinius Primus, que desarrolló un completo cursus honorum local, donó un [mac]ellum cum columnis et [- - et] statuis et ponderario et tho[l]o (ILAlg. II.3, 7929), siendo posible identificar una de las tabernae interiores como ponderarium ${ }^{69}$, donde además se halló una mensa ponderaria con diez orificios de los que quizás pendían los pesos y balanzas oficiales (ILAlg. II.3, 7938); de Thibilis, donde la mensa con medidas "structor(ias) et fabril(es)" fue hallada,

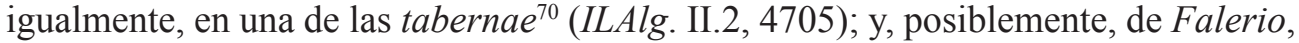
donde el octovir augustal M. Allius Agenor donó un pon[derarium] cum ponderibus et men[suris], indicando por lo tanto, de manera explícita, los instrumentos de medición que allí se recogían ${ }^{71}(A E 1922,89)$.

Pero sin duda uno de los casos más destacados al respecto es el de Tibur, donde el magister Herculaneus M. Varenus Diphilus donó un ponderarium que distaba pocos metros de la basílica (Inscr. It. IV.1, 221-223). Se trata de una estancia de pequeñas dimensiones en el que se hallaron dos tabulae -la primera de ellas más grande y con cuatro orificios diferentes para la medición y la segunda más pequeña con otras dos cavidades-con idéntica altura y que distaban entre sí $60 \mathrm{~cm}$. estando prácticamente encastradas en la pared. En el pavimento de mosaico se halló un pequeño orificio que podría ser interpretado como una salida para la evacuación de líquidos. Además, se hallaron in situ tres de las seis piezas correspondientes al juego de pesos del que estaría dotado el ponderarium, además de una statera. Finalmente, gracias a la última de estas inscripciones conocemos que un personaje ignoto -que posiblemente no sea identificable con el propio Diphilus, sino un colega suyo posterior, perteneciente también a los cultores Hercules - restituyó, quizás investido de la aedilicia potestas, los pesos instaurados años antes por aquel munificente ciudadano (Inscr. It. IV.1, 223) ${ }^{72}$.

Un ejemplo paralelo al de Tibur puede ser documentado en Hippo Regius. Al norte del macellum de esta comunidad se descubrió una estancia anexa de dimensiones modestas en la que se conservaban dos grandes bloques de piedra, uno al lado del otro que presentan cavidades que podrían haber sido destinadas a encastrar una balanza. Asimismo, en las excavaciones del mercado fueron recuperadas balanzas y pesos

construirse ágoras comerciales para separar esta actividad de la puramente política y religiosa. Además, estas ágoras comerciales influirán de manera decisiva en muchos de los macella romanos (ToRRECILLA, 2003, 309 ss.). En cuanto a la inclusión de ponderaria en basílicas, véase M. ARNolDs (2007, 40-41). Un ejemplo de ello lo encontramos en Cuicul, donde fue hallada una mensa para medidas en las salas del sótano de la basílica, muy cerca del macellum (De RuYt, 1983, 66, n. 33). Finalmente, es frecuente encontrar mensae de este tipo en el mismo foro e incluso otros lugares de la ciudad (ead., 321).

${ }^{69}$ Cfr. C. De Ruyt $(1983,64-66)$ y C. Briand-Ponsart (2008, 111-112).

70 De Ruyt, 1983, 205-206.

71 C. Delplace $(1998,189-193)$ creyó poder identificar el ponderarium con unas estructuras murarias halladas en Falerio en la década de 1910, aunque es posible que el lugar del hallazgo del epígrafe no coincidiera con ese edificio ( $c f r$. MARALDI, 2002, 45).

${ }^{72}$ La lectura de esa inscripción fragmentaria no permite, como decimos, saber con seguridad si fue Diphilus u otro personaje el encargado de restituir los instrumentos de medición. No obstante, M. JACZYNOWSKA $(1981,642-643)$ opta porque fueran personajes diferentes y separados por cierto arco temporal, dado que Diphilus fue magister Herculaneum y el personaje ignoto, investido de la potestad edilicia como decimos, porta el título de Herculaneus Augustalis. En los años que median entre ambos personajes se habría producido, por lo tanto, el cambio de titulación, seguramente a partir de mediados del s. I d.C. 
diversos. Es muy probable que nos encontremos ante un ponderarium, pese a que no contemos con inscripciones que confirmen con plena seguridad esta hipótesis, dado que los dos grandes bloques, que conformarían una "mensa ponderaria", son anepigráficos $^{73}$. A este último respecto, sí se ha conservado una inscripción muy fragmentada que documenta la restitución del macellum y en la que se pudo hacer referencia al ponderarium o a alguno de los instrumentos de medición que allí se custodiaban ${ }^{74}$.

Sin embargo, no siempre existieron habitáculos realizados específicamente para la función que estamos analizando, dado que en otras ocasiones los instrumentos de medición o ponderación estuvieron emplazados en espacios abiertos, generalmente en el foro, en el area, la porticus o tholos macelli o incluso en la basílica. Efectivamente, en ocasiones se documentan estelas o bases pétreas que, de forma más o menos compleja, contenían los instrumentos adecuados para el pesaje y/o medida de mercancías y que también son conocidos, en la historiografía moderna, como ponderaria o mensae ponderariae ${ }^{75}$. El caso más llamativo es el de Philippi donde se halló una estela erigida por los ediles de esta comunidad y financiada gracias a las multas impuestas por estos magistrados o a partir de la confiscación de pondera con un peso de cuarenta y cuatro libras $(A E 1935,49)^{76}$. Dicha estela debió tener fijada una balanza posiblemente en equilibrio, un juego de pesos y presentaría encastrada en su cara frontal una mensa, seguramente para la medida de áridos. Casos paralelos al de Philippi pueden ser documentados por otras inscripciones como por ejemplo CIL IX, 1656 de Beneventum, donde el edil M. Tatonius Firmianus basem cum statera et ponder(ibus) aeneis de suo fec(it); y quizás CIL XI, 6375 de Pisaurum, donde los ediles $C$. Septimius Candidus y P. Munatius Celer stateram aerea $(m)$ et pondera... ponenda curaverunt. En ocasiones, todavía se encuentran in situ algunas de estas piezas, como se constata en el macellum de Cuicul (ILAlg. II.3, 7938), si bien sabemos por la arqueología que este edificio contó con un lugar específico destacado cuya funcionalidad era el pesaje de los productos adquiridos en el mercado, como además demuestra otra inscripción ya comentada ${ }^{77}$ (ILAlg. II.3, 7929).

En cuanto a las llamadas mensae ponderariae, este tipo de instrumento estuvo destinado, generalmente, a la medición de áridos o líquidos ${ }^{78}$. Estaban dotadas de

73 Véase C. De Ruyt (1983, 92-93).

74 La lectura de la inscripción, según C. DE RuYT (1983, 93) es la siguiente: [- - -]iae vetus(tatis) [- - -] / [- - ] macelli totiu(s) [- - - - - ]. La expresión final pudo referirse a "todos sus ornamentos" e incluso citar explícitamente alguno de los instrumentos de medición del ponderarium, de forma paralela a lo que tenemos documentado en otros casos (p. ej. CIL VIII, 9062).

75 A pesar de que, como comentamos anteriormente, estas expresiones son más propias de la historiografía actual y no fueron utilizadas por los romanos (Michon, 1969, 547).

76 Sobre esta inscripción, véase C. De Ruyt (1993, 136) y, especialmente, P. LemerLe (1934, $457-$ 461).

77 En el mercado de Cuicul se conserva, además, una mensa moldurada para las medidas de capacidad y longitud. Dado que le falta la moldura en su parte posterior, quizás la pieza estuvo encastrada en un muro, posiblemente dentro del cercano ponderarium.

78 Sobre la tipología de estas mensae, véase W. DÉonna (1913, 169 ss.). La finalidad de este tipo de soporte es más variada de lo que en un principio cabría esperar, existiendo, por ejemplo, "mensur(as) olear(ias)" (CIL V, 4468 y VIII, 9666); "mensuras frument(arias)" (AE 1922, 12); "mensuras structor(ias) et fabril(es)" (ILAlg. II.2, 4705); "mensur(as) liquarias" (CIL XI, 5695); "[mens] uras vas[cularias(?)]" (CIL X, 5797); medidas para la sal (CIL VIII, $1180=14310)$; para trigo, cebada y 
diferentes cavidades que en algunos casos presentan orificios de salida para la recuperación de la mercancía, mientras que, en otros casos, esas cavidades sirvieron como simples soportes para vasos fabricados en metal en los que se realizarían las mediciones, lo que explica que en algunas ocasiones hallemos en estas mensae restos de crampones o grapas de metal que servirían para la sujeción de esos vasos. No obstante, como hemos tenido ocasión de comentar, algunas de estas mensae pudieron servir como soporte para balanzas o staterae y contendrían un juego de pesos para realizar las ponderaciones.

Finalmente sólo nos queda comentar que en ocasiones se pudieron adoptar fórmulas intermedias adaptando una parte del macellum para custodiar los pesos y medidas oficiales. Este pudo ser el caso del llamado mercado de Sertius en Lepcis Magna, donde se delimitó un espacio mediante tabiques verticales cuya finalidad quizás fue la de contener este tipo de instrumental, concretamente para medidas de capacidad y longitud, todo ello cercado por rejas que aprovecharon, además, dos de las columnas del pórtico para completar el cercado ${ }^{79}$.

Como hemos podido comprobar a lo largo de nuestro estudio, el Estado romano estuvo interesado en la difusión de modelos estandarizados de pesos y medidas que facilitaran los intercambios comerciales por todo el Imperio. Para ello fue indispensable que las diferentes comunidades bajo su dominio fueran conociendo y adoptando el sistema romano de pesos y medidas y, aunque no se consiguió una completa universalización del mismo, sí hemos demostrado que éste se difundió lo suficiente como para cumplir los objetivos deseados. Las fuentes nos permiten comprobar cómo diferentes magistrados desde la Urbs lograron que dicho modelo se generalizara y tenemos suficientes fuentes para creer que prácticamente todos los municipios y colonias romanos e incluso centros administrativos menores como los pagi contaron entre sus infraestructuras cívicas con ponderaria $\mathrm{o}$, al menos, instrumentos de medición y pesaje para la comprobación de que las transacciones comerciales eran realizadas según lo convenido y conforme a la ley romana. En general y pese a la evolución del sistema administrativo en la capital, los municipios y colonias del Imperio continuaron confiando a los ediles la supervisión de los pesos y medidas en sus respectivas comunidades, aunque no debemos olvidar que otros magistrados, generalmente de rango superior, pudieron involucrarse en dichas tareas, especialmente si los ordines decurionum locales, mediante el correspondiente decreto, lo estimaban oportuno.

vino (ILAlg. II.3, 8023); o para vino y cereales (AE 1954, 155). Aunque mucho más extraordinarios, pudieron incluso existir pondera para el pesaje de determinados productos como el pan (CIL IX, 2854; cfr. BROEKAERT, 2008, 205-206).

79 De Ruyt, 1983, 196. 


\section{Bibliografía}

ALFÖLDY, G. (1977): Konsulat und Senatorenstand unter den Antoninen: prosopographische Untersuchungen zur senatorischen Führungsschicht. Bonn.

ARNOLDS, M. (2007): Funktionen republikanischer und frühkaiserzeitlicher Forumsbasiliken in Italien (Dissertation, Elektronische Ressource). Universität Heidelberg.

ASHBY, T. (1906): "The Classical Topography of the Roman Campagna II", PBRS 3, 3-212.

BARRESI, P. (1994): "Sopravvivenze dell'unità di misura punica e suoi rapporti con il piede romano nell'Africa di età imperiale", en L'Africa Romana VIII, Roma, 479-502.

BERGER, A. (1953): Encyclopedic Dictionary of Roman law. Filadelfia.

BERMEJO MELÉNDEZ, J.; CAMPOS CARRASCO, J. M. (2009): "La sala de los ediles de Arucci/Turobriga. Officina ponderaria aruccitana", Saguntum 41, 187198.

BERRENDONNER, C. (2009): "La surveillance des poids et mesures par les autorités romaines: l'apport de la documentation épigraphique latine", Cahiers Glotz XX, 351-370.

BERT LOTT, J. (2004): The Neighborhoods of Augustan Rome. Cambridge.

BISPHAM, E. H. (2007): From Asculum to Actium. The municipalization of Italy from the Social War to Augustus. Oxford.

BORGHESI, B. (1865): Oeuvres complètes. II: oeuvres épigraphiques. París.

BRIAND-PONSART, C. (2008): "Pratiques et institutions municipales a Cuicul (Djemila), cité de Numidie", en Berrendoner, C.; Cébeillac-Gervasoni, M.; Lamoine, L. (eds.), Le quotidien municipal dans l'Occident romain, Clermont-Ferrand, 103-119.

BROEKAERT, W. (2008): "Bread Basket on the Marketplace? A Short Note on CIL IX, 2854 (ILS, 5591)", ZPE 167, 204-206.

CABALLOS, A.; FERNÁNDEZ, F. (2002): "Nuevos testimonios andaluces de la legislación municipal flavia", ZPE 141, 261-282.

CAMODECA, G. (1979): “Curatores rei publicae I”, ZPE 35, 225-236.

CAMPOS CARRASCO, J. M.; BERMEJO MELÉNDEZ, J. (2007): "Manifestaciones de culto imperial en el foro de la ciudad hispanorromana de Turobriga", en Nogales Basarrate, T.; González Fernández, J. (eds.), Culto imperial: política y poder, Roma, 251-273. 
CÉBEILLAC-GERVASONI, M. (1990): "L'évérgetisme des magistrats du Latium et de la Campanie des Gracques à Auguste à travers les témoignages épigraphiques", MEFRA 102.2, 699-722.

CÉBEILLAC-GERVASONI, M.; CALDELLI, M. L.; ZEVI, F. (2010): Epigrafia latina. Ostia: cento iscrizioni in contesto. Roma.

CHAVES TRISTÁN, F. (1982): "Instrumentos de medida romanos hallados en Andalucía”, Zephirus XXXIV-XXXV, 219-222.

CHAVES TRISTÁN, F.; PLIEGO VÁZQUEZ, R. (2007): “Instrumentos de medida de pesos en la 'Hispania' antigua", Sautuola 13, 237-250.

CHELOTTI, M.; MENNELLA, G. (1994): "Letture e riletture epigrafiche nella Regio II", ZPE 103, 159-172.

CLOUD, J. D.

(1985): "A lex de ponderibus (Festus, p. 288 L)", Athenaeum 63, 405-418.

(1996): "Lex Silia", en Crawford, M. H. (ed.), Roman Statutes, vol. 2, Londres, 737-739.

CORBIER, M. (2006): Donner à voir, donner à lire. Mémoire et communication dans la Rome ancienne. París.

CORTI, C.

(2001a): "Pesi e misure nei commerci, arti, mestieri e professioni", en Corti, C.; Giordani, M. (eds.), Pondera. Pesi e mesure nell 'Antichità. Campogalliano, 143166.

(2001b): "Pesi e contrappesi", en Corti, C.; Giordani, M. (eds.), Pondera. Pesi e mesure nell'Antichità. Campogalliano, 191-212.

CRAWFORD, M. H. (1974): Roman Republican Coinage. Cambridge.

DARROU, G. (1993): "Quelques instruments de mesures de capacite del'Antiquite à l'Empire romain", en Ahreus, D.; Rottländer, R. C. A. (eds.), Ordo et Mensura II. II Internationaler interdisziplinärer Kongress für Historische Metrologie, St. Katharinen, 315-335.

DE LIGT, L. (1993): Fairs and Markets in the Roman Empire: Economic and Social Aspects of Periodic Trade in a Pre-Industrial Society. Amsterdam.

DELPLACE, C. (1998): "Quelques cas d'évérgetisme dans la région V augustéene (Picenum)", en G. Paci (ed.), Epigrafia Romana in area Adriatica: Actes de la IXe rencontre franco-italienne sur l'épigraphie du monde romain, Pisa-Roma, 189198.

DÉONNA, W. (1913): “Tables de mesures de capacité anciennes et modernes", REA XV, 167-180.

DE RUYT, C. (1983): Macellum. Marché alimentaire des Romains. Amsterdam.

DE UREÑA, R. (1915): “El modius de Ponte Puñide”, BRAH 66, 485-507. 
DI VITA-ÉVRARD, G. (2002-03): "Sur deux inscriptions votives bilingues de Sabratha et de Lepcis Magna", Ant. Afr. 38-39, 297-306.

DUNCAN-JONES, R. P. (1994): Money and Government in the Roman Empire. Cambridge.

FOLCANDO, E. (1996): “Lex municipii Compsani”, QS 43, 303-308.

GARCÍA MORCILLO, M. (2005): Las ventas por subasta en el mundo romano: la esfera privada. Barcelona.

GASPERINI, L. (1991): "Spigolature epigraphiche valdostane", en Epigrafia. Actes du colloque en mémoire de A. Degrassi, Roma, 711-723.

GATTI, G. (1881): “Della legenda 'exact. ad Artic.' nelle iscrizioni ponderarie con appendice di G. B. De Rossi”, Annali dell'Instituto di correspondenza archeologico 53, 181-203.

HAENSCH, R.; WEISS, P.

(2005): "Gewichte mit Nennung von Statthaltern von Pontus et Bithynia", Chiron 35, 443-498.

(2007): "Statthaltergewichte aus Pontus et Bithynia. Neue Exemplare und neue Erkenntnisse", Chiron 37, 183-218.

JACZYNOWSKA, M. (1981): “Le culte de l'Hercule romain”, $A N R W 17.2$, 631-661.

KURYLOWICZ, M. (2000): “Zur Marktpolizei der römischen Ädilen”, en Au-delà des frontières. Mélanges de droit romain offerts à W. Wolodkiewicz, Varsovia, vol. I, 439-456.

LAMBERTI, F.

(1993): Tabulae Irnitanae. Municipalità e ius Romanorum. Nápoles.

(1994): "Un caso di "mensurae iniquae", Labeo 40.3, 364-369.

LAMOINE, L.

(2003-06): "Le Cippe de L. Sévérius Sévérinus", Bulletin de l'École Antique de Nîmes 26, 3-7.

(2009): Le pouvoir local en Gaule romaine. Clermont-Ferrand.

LANGHAMMER, W. (1973): Die rechtliche und soziale Stellung der Magistratus Municipales und der Decuriones in der Übergangsphase der Städte von sich selbstverwaltenden Gemeinden zu Vollzugsorganen des spätantiken Zwangsstaates (2.-4. Jahrhundert der römischen Kaiserzeit). Wiesbaden.

LE BOHEC, Y. (2000): The Imperial Roman Army. Londres-Nueva York.

LEMERLE, P. (1934): “Inscriptions latines et grecques de Philippes. I. Inscriptions latines", $B C H$ 58, 448-483.

LEPELLEY, C. (1981): Les cités de l'Afrique romaine au Bas-Empire. Vol. II. París.

MARALDI, L. (2002): Falerio. Roma. 
MARENGO, S. M. (1999): "Le multae", en Il capitolo delle entrate nelle finanze municipali in Occidente ed in Oriente, Roma-Paris, 73-84.

MELCHOR, E. (1994): "Summae honorariae y donaciones ob honorem en la Hispania romana", Habis 25, 193-212.

MICHON, E. (1969): “Ponderarium”, en Daremberg, Ch.; Saglio, E. (eds.), Dictionnaire des Antiquitès Grecques et Romaines IV, París, 547-548.

ORDÓÑEZ AGULLA, S.; SAQUETE CHAMIZO, J. C. (2009): "Una dedicación votiva ex multis pistorum hallada en la Bética", Habis 40, 197-240.

PÉREZ ZURITA, A. D. (2011): La edilidad y las élites locales en la Hispania romana. La proyección de una magistratura de Roma a la administración municipal. Córdoba-Sevilla.

PFLAUM, H.-G. (1960): Les carrières procuratoriennes équestres sous le Haut-Empire romain. Vol. II. París.

REINARD, $\mathrm{P}$. (2008): "Eine Eichinschrift auf einem römischen Bronzegewicht", ZPE 165, 291292.

(2009): "Neue Bronzegewichte mit lateinischen Inschriften", $Z P E$ 171, 261-264.

RICHARDSON JR., L. (1992): A new topographical dictionary of ancient Rome. Baltimore.

ROBINSON, O. F. (1992): Ancient Rome. City planning and administration. Londres-Nueva York.

RODRÍGUEZ NEILA, J. F. (2006): “Epula y cenae públicos financiados por las ciudades romanas”, Cahiers Glotz XVII, 123-142.

RODRÍGUEZ NEILA, J. F.; MELCHOR, E. (2000): "Evergetismo y cursus honorum de los magistrados municipales en las provincias de la Bética y Lusitania", en Castillo, C.; Navarro, F. J.; Martínez, R. (eds.), De Augusto a Trajano. Un siglo en la historia de Hispania, Pamplona, 139-238.

ROTONDI, G. (1912): Leges publicae populi Romani. Milán.

RUCIŃSKI, S. (2009): Praefectus Urbi. Le Gardien de l'ordre public à Rome sous le Haut-Empire Romain. Poznan.

SABBATINI TUMOLESI, P. (1988): Epigrafia anfiteatrale dell'Occidente romano. Vol. I: Roma. Roma.

SALOMIES, O. (2003): "A Study of CIL XIV, 375, an Interesting Inscription from Ostia", Arctos 37, 133-157.

SCUDERI, R. (2008): "Iscrizioni su opere pubbliche in Transpadana", en Basso, P. et alii (eds.), Est enim ille flos Italiae... Vita economica e sociale nella Cisalpina romana, Verona, 243-261. 
SERRAO, F. (2000): "Impresa, mercado, diritto. Riflessioni minime", en Lo Cascio, E. (ed.), Mercati permanenti e mercati periodici nel mondo romano, Bari, 31-67.

SHERK, R. K. (1970): The Municipal Decrees of The Roman West. Buffalo.

STYLOW, A. U.; GIMENO, H. (2001): "Remissis cenis publicis: las reglas de juego del evergetismo. A propósito de CIL II 1046 con un apéndice sobre CIL VIII 11058", Faventia 23/2, 97-109.

TORRECILLA, A. (2003): "El origen del macellum romano en el ágora comercial griega", Bolskan 20, 309-324.

TRAN, N.

(2006): Les membres des associations romaines: le rang social des collegiati en Italie et en Gaules sous le Haut-Empire. Roma.

(2008): "Les cités et le monde du travail urbain en Afrique romain", en Berrendonner, C.; Cébeillac-Gervasoni, M.; Lamoine, L. (eds.), Le quotidien municipal dans l'Occident romain, Clermont-Ferrand, 333-348.

WALTZING, J. P. (1896): Étude historique sur les corporations professionnelles ches les Romains depuis les origines jusqu'à la chute de l'Empire d'Occident II. Bruselas.

WEISS, P. (2005): "Von Perinth in die Dobrudscha nach Bithynien und Westkleinasie. Regionale und überrregionale Gestaltungsweisen bei den Marktgewichten in der Kaiserzeit", Chiron 35, 405-442.

WILKINS, P. I. (1988): “Amphitheatres and Private Munificence in Roman Africa. A New Text from Thuburnica", ZPE 75, 215-221. 